\title{
Prednisolone in the treatment of airflow obstruction in adults with cystic fibrosis
}

\author{
CHARLES FA PANTIN, ROBERT J STEAD, MARGARET E HODSON, \\ JOHN C BATTEN
}

From the Cardiothoracic Institute, Brompton Hospital, London

ABSTRACT The effect of oral prednisolone on the lung function of 20 adult patients with cystic fibrosis who had severe stable airflow obstruction was assessed in a placebo controlled study, blind to the patients. Placebo tablets were followed by prednisolone given in a median dose of $0.48 \mathrm{mg} / \mathrm{kg}$ body weight/day $(20 \mathrm{mg} /$ day in 11 patients, $30 \mathrm{mg} /$ day in nine patients), each for three weeks. No significant improvement was seen in lung function in the group after receiving prednisolone, and none of the individual patients had clinically useful improvements in lung function. Atopic subjects showed an improvement in evening recordings of peak expiratory flow rate (PEF) while taking prednisolone $(\mathrm{p}<0.05)$. Significant deterioration in forced expiratory volume in one second $\left(F E V_{1}\right)$ and forced vital capacity (FVC) was seen after withdrawal of prednisolone. Two patients developed pneumothoraces while taking prednisolone.

Patients with cystic fibrosis characteristically develop increasing airflow obstruction as their disease progresses. In other disease processes associated with airflow obstruction, such as asthma and chronic bronchitis, corticosteroids have been shown to be beneficial in varying proportions of patients. We have occasionally found that corticosteroids have improved pulmonary function in individual patients with cystic fibrosis when other treatment, such as intensive physiotherapy, antibiotics, and bronchodilator drugs, have failed. Lewiston et al gave large doses of prednisone $(2 \mathrm{mg} / \mathrm{kg}$ body weight/day) to children with cystic fibrosis who had symptoms that they considered indicated hypersensitivity, such as fevers, arthritis, obstructive lung disease unresponsive to bronchodilator treatment, and allergic aspergillosis, and who had increased serum complement $\mathrm{Clq}$ binding activity. Prednisone was given during an acute illness, presumably with other treatment for their pulmonary disease, and a significant fall in Clq binding activity was seen in association with improvement in FVC. They concluded that there is a population of patients with cystic fibrosis who may benefit from vigorous antiinflammatory treatment.

There are inherent difficulties in assessing changes

Address for reprint requests: Dr RJ Stead, Department of Cystic Fibrosis, Cardiothoracic Institute, Brompton Hospital, London SW3 6HP.

Accepted 23 July 1985 in respiratory function in response to treatment in patients with cystic fibrosis because of the variation that occurs as the chronic pulmonary infection waxes and wanes. In our investigation therefore-to our knowledge the first controlled study of corticosteroids on lung function in patients with this diseasewe chose to study subjects with severe airflow obstruction who were clinically stable.

\section{Methods}

A power calculation was performed to estimate the number of patients required to demonstrate a significant influence of corticosteroids on lung function in cystic fibrosis. Two recent readings of peak expiratory flow rate (PEF), $\mathrm{FEV}_{1}$, and forced vital capacity (FVC) were taken from the outpatient recordings of 10 clinically stable patients who later entered the study, and were used in a two way analysis of variance and power calculation. ${ }^{2}$ This suggested that if a mean change of up to $331 \mathrm{~min}^{-1}$ in PEF, $100 \mathrm{ml}$ in $\mathrm{FEV}_{1}$, and $200 \mathrm{ml}$ in FVC were regarded as clinically insignificant, then studying 20 patients with paired data would leave a $5 \%$ chance of missing such changes at the $5 \%$ level of statistical significance.

\section{PATIENTS}

We studied 20 adult patients ( 16 male, four female) with cystic fibrosis established by sweat analysis (sweat sodium $>70 \mathrm{mmol} / \mathrm{l}$ ) who had typical clinical features. They were selected on the basis of an FEV 
less than or equal to $50 \%$ of the predicted value for their sex, age, and height. ${ }^{3}$ They had been clinically stable for at least one month before the study and had not required changes in treatment for their respiratory disease, except courses of oral antibiotics in some cases. All the patients performed regular chest physiotherapy. Patients who suffered from diabetes mellitus, those who were already taking corticosteroid drugs, and those who had previously been in heart failure were excluded from the study. Informed consent was obtained from all subjects.

The median age of the patients was 23 years (range 17-51). Eleven of the patients were atopic, with at least one immediate reaction of $2 \mathrm{~mm}$ in diameter or more to common inhaled allergens on skinprick testing. Ten of these patients had positive skin reactions to Aspergillus fumigatus. In five patients precipitins to $A$ fumigatus were present in serum. Three patients had a blood eosinophilia $(>0.4 / \mathrm{nl})$ but none of the patients fulfilled the criteria for allergic bronchopulmonary aspergillosis. ${ }^{4}$ In 13 of the patients Pseudomonas aeruginosa was present in sputum cultures at the start of the study, and in five of the remainder Staphylococcus aureus or Haemophilus influenzae, or both, were present. In two patients no pathogens were cultured. Fourteen patients were receiving inhaled salbutamol on a regular basis. On entry to the study only two patients showed an increase of more than $15 \%$ in $\mathrm{FEV}_{1}$ following $200 \mu \mathrm{g}$ of salbutamol from a metered dose pressurised inhaler. Other regular medication taken by the patients included inhaled antibiotics (9), oral antibiotics (12), pancreatic supplements (19), cimetidine (4), vitamins (18), oral contraceptives (2), and bromhexine (1). The chest radiograph in each patient showed typical features of cystic fibrosis. Further clinical data on the 19 patients who completed the study are presented in table 1 .

\section{DESIGN OF THE STUDY}

Patients were told that they would receive prednisolone during the study, but otherwise they were unaware of the design. On entry to the study the patients were assessed in the clinic (visit A). They then received placebo tablets for three weeks in a once

Table 1 Characteristics of the 19 patients who completed the study

\begin{tabular}{|c|c|c|}
\hline & Median & Range \\
\hline Weight (kg) & 49 & $32-76$ \\
\hline Weight $\left(\%\right.$ predicted $\left.{ }^{5}\right)$ & 81 & $62-102$ \\
\hline PEF (\% predicted $\left.{ }^{3}\right)$ & 46 & $29-81$ \\
\hline $\mathrm{FEV}_{1}\left(\%\right.$ predicted $\left.^{3}\right)$ & 27 & $16-50$ \\
\hline FVC $\left(\%\right.$ predicted $\left.^{3}\right)$ & 47 & $23-76$ \\
\hline
\end{tabular}

PEF-peak expiratory flow; $\mathrm{FEV}_{1}$-forced expiratory volume in one second; FVC - forced vital capacity. daily morning dose, at the end of which time they were reassessed (visit B). For the next three weeks the patients received prednisolone (Precortisyl, Roussel) $30 \mathrm{mg}$ daily in the morning ( $20 \mathrm{mg}$ daily if their body weight was less than $50 \mathrm{~kg}$ ), having the same number of tablets a day as they had received during the placebo period. At the end of this time they were again reassessed (visit $C$ ) and the daily dose of prednisolone was tailed off by $5 \mathrm{mg}$ every three days. The patients were finally reassessed at the end of this "follow up" period (visit D) seven weeks after they had started taking prednisolone.

At each assessment a clinical examination was performed. PEF was measured on a Wright peak flow meter and $\mathrm{FEV}_{1}$ and FVC on a Vitalograph wedge spirometer. In each case the highest reading after three attempts was recorded. These measurements were repeated 10 minutes after the patients had received $200 \mu \mathrm{g}$ salbutamol from a metered dose pressurised inhaler. For each variable the highest reading, either before or after bronchodilator, was used in analysis. Patients were graded according to the Medical Research Council (MRC) scoring of breathlessness, ${ }^{6}$ in which grade 1 represents breathlessness on strenuous exertion only and grade 5 represents being too breathless to leave the house or breathlessness after undressing. The distance they were able to walk along a level corridor in six minutes was measured. Body weight was recorded. A sputum sample was sent for culture for bacterial pathogens. Venepuncture was performed about two hours after the last meal for a blood eosinophil count and estimation of plasma glucose concentration.

Throughout the study the patients completed a daily diary card on which they recorded PEF, which they measured twice a day after physiotherapy in the morning and evening with a miniature Wright peak flow meter. They were instructed to test their urine for the presence of glucose twice a week after their evening meal, using Clinistix reagent strips (Ames), and to record the result. Daily sputum volume was recorded on the diary cards on a scale of 0 (none) to 5 (more than a teacupful/24 hours). Similarly, patients scored their sense of general wellbeing and sensation of breathlessness as 3-"better than usual"; 2-"the same as usual"; or 1-"worse than usual." The scores from the diary cards used in analysis were the means of seven days' recordings after entry to the study and before each subsequent visit respectively.

During the study period the number of respiratory infections in each patient was assessed by the number of courses of antibiotics prescribed and any requirement for admission to hospital.

STATISTICAL ANALYSIS

Comparisons were made by Student's paired $t$ test or 
Table 2 Results of clinic assessments (means with standard errors in parentheses)

\begin{tabular}{|c|c|c|c|c|}
\hline & $\begin{array}{l}\text { Visit } A \text { (at entry) } \\
n=19\end{array}$ & $\begin{array}{l}\text { Visit } B \text { (after placebo } \\
n=19\end{array}$ & $\begin{array}{l}\text { Visit C (after prednisolone) } \\
n=19\end{array}$ & $\begin{array}{l}\text { Visit } D \text { (follow up) } \\
n=16\end{array}$ \\
\hline $\begin{array}{l}\text { MRC score of breathlessness } \\
6 \text { minute walking distance }(\mathrm{m}) \\
\operatorname{PEF}\left(1 \mathrm{~min}^{-1}\right) \\
\operatorname{FEV}_{1}(\mathrm{ml}) \\
\operatorname{FVC}(\mathrm{ml})\end{array}$ & $\begin{array}{l}1.3(0.3) \\
577(21) \\
291(19) \\
1163(88)^{*} \\
2227(182)\end{array}$ & $\begin{array}{l}1.4(0.3) \\
585(18) \\
278(20) \\
1145(88) \ddagger \\
2239(195) \ddagger\end{array}$ & $\begin{array}{l}1.1(0.3) \\
601(17) \\
289(18) \\
1173(92) \dagger \\
2292(198) \dagger\end{array}$ & $\begin{array}{l}1.4(0.3) \\
598(23) \\
283(22) \\
1088(98)^{*}+\ddagger \\
2058(233)+\ddagger\end{array}$ \\
\hline
\end{tabular}

Statistical comparisons (Student's paired $t$ test):

${ }^{*}$ Between visits $A$ and $D p<0.05\left(F_{1} V_{1}\right)$.

+ Between visits $C$ and $D_{\mathrm{p}}<0.01\left(\mathrm{FEV}_{1}\right)$ and $<0.001$ (FVC).

\pm Between visits $B$ and $D_{p}<0.05$ (FEV ${ }_{1}$ ) and $<0.001$ (FVC).

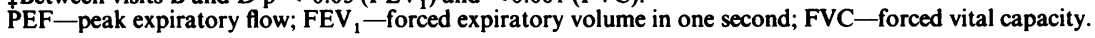

Table 3 Results of diary card recordings (means with standard errors in parentheses)

\begin{tabular}{|c|c|c|c|c|}
\hline & $\begin{array}{l}A \text { (at entry) } \\
n=19\end{array}$ & $\begin{array}{l}B \text { (after placebo) } \\
n=19\end{array}$ & $\begin{array}{l}C \text { (after prednisolone) } \\
n=19\end{array}$ & $\begin{array}{l}D(\text { follow up) } \\
n=15\end{array}$ \\
\hline $\begin{array}{l}\text { PEF }\left(1 \min ^{-1}\right) \text { am } \\
\text { pm } \\
\text { Wellbeing score }(1-3) \\
\text { Breathlessness score }(1-3) \\
\text { Sputum volume score }(0-5)\end{array}$ & $\begin{array}{l}303(20) \\
319(18) \\
1.96(0.07) \\
1.97(0.08)^{*} \\
2.43(0.21)\end{array}$ & $\begin{array}{c}300(19) \\
319(18) \\
1.83(0.09) \\
1.83(0.09)^{*} \\
2.49(0.16)\end{array}$ & $\begin{array}{l}301(16) \\
326(16) \\
1.94(0.15) \\
1.99(0.15) \\
2.59(0.18)\end{array}$ & $\begin{array}{l}311(19) \\
324(21) \\
1.79(0.14) \\
1.70(0.13) \\
2.83(0.2)\end{array}$ \\
\hline
\end{tabular}

Statistical comparison (Wilcoxon's rank test):

${ }^{*} \mathrm{p}<0.05$.

Wilcoxon's rank test as appropriate.

\section{Results}

Of the 20 patients who entered the study, one man was withdrawn while taking prednisolone owing to the development of a pneumothorax. Complete data were obtained from the other 19 patients except at the end of the follow up period: four patients failed to complete diary cards during this period and three patients did not attend at visit D. Tables 2 and 3 review the data obtained at clinic visits and from the diary cards respectively.

\section{LUNG FUNCTION}

No statistically significant changes in lung function at the $5 \%$ level were seen after treatment with prednisolone (between clinic visits $B$ and $C$ in table 2). All the respiratory function variables recorded in the clinic (PEF, FEV, FVC) and the six minute walking distance showed an increase in their means between visits $B$ and $C$, the $95 \%$ confidence limits for the mean differences in PEF being -1 to $231 \mathrm{~min}^{-1}$, in FEV -26 to $82 \mathrm{ml}$, and in FVC -47 to $153 \mathrm{ml}$. PEF rose in 13 out of the 19 patients between these clinic visits, $\mathrm{FEV}_{1}$ in 11 (figure), and FVC in 11; but in no patient did all three variables rise by more than $10 \%$ and in only two did all three rise by $5 \%$. Similarly, no significant change was seen in diary card recordings of PEF following prednisolone (table 3). In fact, the increase in their means between visits $B$ and $C$ was less than the improvements in the respiratory function variables assessed in the clinic. The $95 \%$ confidence limits for the mean difference for PEF recorded in the morning between visits $B$ and $C$ were -17 to $191 \mathrm{~min}^{-1}$, and for PEF recorded in the evening -7 to $221 \mathrm{~min}^{-1}$.

Similarly, there was no significant change in the respiratory variables when the patients were taking placebo (between clinic visits A and B), the $95 \%$ confidence limits for the mean differences in clinic recordings of PEF being -26 to $11 \mathrm{~min}^{-1}$, of $\mathrm{FEV}_{1}$

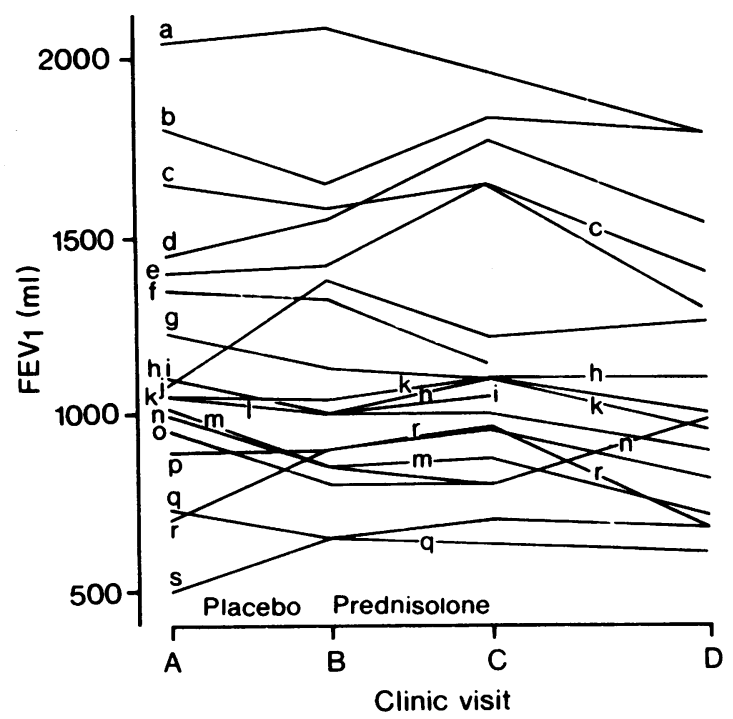

$F E V_{1}$ in individual patients at each clinic visit. 
-81 to $44 \mathrm{ml}$, and of FVC -124 to $149 \mathrm{ml}$. Of the diary card recordings of PEF in the morning and evening the respective confidence limits were -11 to 5 $1 \mathrm{~min}^{-1}$ and -7 to $91 \mathrm{~min}^{-1}$. In the 11 atopic subjects there was a small but significant improvement in diary card evening peak flow recordings between visits $B$ and $C(p<0.05)$, but not in any of the other respiratory function variables measured. In none of the other following subgroups was a significant change in respiratory function seen after prednisolone: (1) male or female; (2) subjects with positive serum aspergillus precipitins; (3) subjects showing improvement in $\mathrm{FEV}_{1}$ after salbutamol of greater than $5 \%$ at visit $A$; and (4) subjects having regular bronchodilator treatment.

\section{CLINICAL AND BACTERIOLOGICAL CHANGES}

There was no significant change in the MRC score of breathlessness during the study. Comparison of diary card recordings, however, for the initial week of the placebo period (A in table 3 ) with those of the final week (B in table 3 ) showed a significant increase in breathlessness in the group. There was no change in breathlessness after prednisolone: 10 patients felt less breathless after prednisolone, three unchanged, and six more breathless. There was also no change in feeling of general wellbeing in the group during the study: eight patients felt improvement in general wellbeing after prednisolone, six felt unchanged, and five felt worse. Body weight showed no consistent change during the period of prednisolone treatment.

There was no significant change in the amount of sputum produced by the patients during the study and no consistent changes in the organisms cultured from the sputum. Five patients required a course of oral antibiotics while taking placebo; these five also required a course during the prednisolone period, as did one additional patient. There were no hospital admissions for treatment of pulmonary infections during the placebo or prednisolone period. During the follow up period there was, however, a significant fall in $\mathrm{FEV}_{1}$ and FVC (table 2). This deterioration was noted clinically and four patients required admission for intensive treatment of their pulmonary condition, including intravenous antibiotics.

Two patients developed pneumothoraces while taking prednisolone; one of these required a pleurodesis and was withdrawn from the study. One patient developed mild fluid retention with a slight increase in jugular venous pressure and hepatomegaly. Three patients developed glycosuria, which resolved after they had discontinued prednisolone, but in only one patient was a two hour postprandial plasma glucose concentration greater than $10 \mathrm{mmol} / \mathrm{l}(180 \mathrm{mg} /$ $100 \mathrm{ml}$ - namely $11.5 \mathrm{mmol} / \mathrm{l}(207 \mathrm{mg} / 100 \mathrm{ml})$.

\section{Discussion}

This study suggests that prednisolone given in standard doses for three weeks does not significantly improve airflow obstruction in patients with cystic fibrosis. This is surprising since there are several features of the disease suggesting that a response might be seen. The incidence of atopy is increased in patients with cystic fibrosis and several studies have shown positive skin reactions on prick testing in from $42 \%$ to $88 \%$ of patients. ${ }^{7}$ A large proportion of patients with positive skin reactions also have reactions to $A$ fumigatus and a minority of these patients may have allergic bronchopulmonary aspergillosis associated with fleeting pulmonary shadows, ${ }^{8}$ although none of our patients was in this category. Bronchial reactivity was also found in one study to be increased in patients with cystic fibrosis, ${ }^{9}$ though in that study only $14 \%$ of older patients showed a rise in $\mathrm{FEV}_{1}$ of over $15 \%$ after an inhaled sympathomimetic. Generally the response to inhaled bronchodilators seems to be small and variable.

There are several possible reasons for our negative result. Our patients were chosen for their severe airflow obstruction and possibly the disease had progressed so far that this obstruction had become fixed. Conceivably therefore patients who had less severe pulmonary disease might have shown a greater response. Corticosteroids may also be useful in maximising lung function after an infective exacerbation, but less helpful in patients who are clinically stable. The order of the treatment periods was not randomised because of uncertainty over the duration of the carry over effect of prednisolone in cystic fibrosis. Introducing a "washout" interval between the two treatment periods would have made the study unacceptably long in view of the natural variability of the clinical state of patients with this disease. This variability was possibly reflected in our study by the small increase in breathlessness and fall in PEF in the clinic seen during the placebo period. Hence the study was open to the investigators but the result is negative, which is opposite to the most likely bias introduced by this factor. This bias may explain the trend towards higher pulmonary function after prednisolone.

It has been suggested that prednisolone and other immunosuppressive drugs may be of benefit in breaking the vicious circle of inflammation in the lungs of patients with bronchiectasis. ${ }^{10} \mathrm{~A}$ treatment period of three weeks as used in our study would not permit this hypothesis to be tested. Several patients attending our adult cystic fibrosis clinic have shown improvement in lung function when corticosteroid treatment was given for many months, and it remains possible that prednisolone may be effective when given for longer periods. 
The dosage regimen in this study produced a median daily dose of $0.48 \mathrm{mg} / \mathrm{kg}$ body weight (equivalent to $34 \mathrm{mg} /$ day in a $70 \mathrm{~kg}$ man), with a range of $0.40-0.63 \mathrm{mg} / \mathrm{kg} / \mathrm{day}$. This regimen would seem to fit in well with accepted practice in the use of prednisolone in other diseases causing airflow obstruction. The pharmacokinetics of prednisolone have not, however, been studied in patients with cystic fibrosis. Preliminary data from our department suggest that absorption of prednisolone is not reduced but is delayed in this disease, with a consequent reduction in peak plasma concentration after an oral dose. Since there is no information on what result these changes may have on the clinical effect of prednisolone, it remains possible that larger doses than we used are necessary to reduce airflow obstruction in these patients.

The deterioration seen in many patients in this study after steroids had been discontinued is a matter for concern. Whereas there is no evidence that the patients were more susceptible to pulmonary infections while taking corticosteroid treatment, they did appear to have an increased frequency of exacerbations when the drug was withdrawn. The other feature causing concern was the development of pneumothoraces in two patients while they were taking prednisolone. Pneumothoraces have previously been associated with the use of prednisolone in the presence of Staphylococcal pneumonia. ${ }^{11}$ A recent survey, however, showed that they occurred in nearly $20 \%$ of older patients with cystic fibrosis, ${ }^{12}$ of whom $96 \%$ had an $\mathrm{FEV}_{1}$ of less than $50 \%$ of the predicted value and were therefore comparable to patients selected for our study. Furthermore, no association has so far been found between the occurrence of pneumothorax and the use of corticosteroids in cystic fibrosis.

Despite this negative result corticosteroids may still have a part to play in treating the pulmonary disease in cystic fibrosis. Allergic bronchopulmonary aspergillosis is difficult to diagnose in this condition but in the small minority of adult patients who have all the features, including eosinophilia, positive skin reactions to aspergillus, and fleeting pulmonary shadows, corticosteroids are clearly indicated in the hope of preventing further bronchial wall damage. Further studies are necessary to determine whether corticosteroids are indicated in other subgroups of patients with cystic fibrosis and, if so, in what way they should be used.

RJS is supported by the Frances and Augustus Newman Foundation. We would like to thank Mrs Kalpana Magecha, Pharmacy Department, Brompton Hospital, for her assistance and Miss $\mathrm{S}$ Hockley for typing the manuscript.

\section{References}

1 Lewiston NJ, Moss RB. Circulating immune complexes decrease during corticosteroid therapy in cystic fibrosis [abstract]. Pediatr Res 1982;16:354A.

2 Armitage P. Statistical methods in medical research. Oxford: Blackwell Scientific Publications, 1971.

3 Cotes JE. Lung function: principles and application in medicine. Oxford: Blackwell Scientific Publications, 1979.

4 McCarthy DS, Pepys J. Allergic broncho-pulmonary aspergillosis. clinical immunology: (1) Clinical features. Clin Allergy 1971;1:261-86.

5 Jelliffe DB. The assessment of the nutritional status of the community. Geneva: World Health Organisation, 1966.

6 Fletcher CM, Elmes PC, Fairbairn AS, Wood CH. The significance of respiratory symptoms and the diagnosis of chronic bronchitis in a working population. $\mathrm{Br}$ Med J 1959;ii:257-66.

7 Hodson ME, Warner JO. Immunology. In: Cystic fibrosis. Hodson ME, Norman AP, Batten JC, eds. London: Baillière Tindall, 1983:ch 5 .

8 Mearns MB, Young W, Batten JC. Transient pulmonary infiltrations in cystic fibrosis due to allergic aspergillosis. Thorax 1965;20:385-92.

9 Tobin MJ, Maguire O, Reen D, Tempany E, FitzGerald MX. Atopy and bronchial reactivity in older patients with cystic fibrosis. Thorax 1980;35:807-13.

10 Cole P. A new look at the pathogenesis and management of persistent bronchial sepsis: a "vicious circle" hypothesis and its logical therapeutic connotations. In: Davies RJ, ed. Strategies for the management of chronic bronchial sepsis. Oxford: Medicine Publishing Foundation, 1984.

11 Olesen KH, Quaade F. Pneumothorax accompanying Staphylococcal pneumonia in patients treated with steroids. Lancet 1961;i:535-6.

12 Penketh ARL, Knight RK, Hodson ME, Batten JC. Management of pneumothorax in adults with cystic fibrosis. Thorax 1982;37:850-3. 